\title{
Trichoderma species in biological control of formae specialis of Fusarium oxysporum
}

\section{Grzyby rodzaju Trichoderma w biologicznej ochronie roślin przed formami specjalnymi Fusarium oxysporum}

\author{
Leszek B. Orlikowski, Czesław Ślusarski
}

\section{Summary}

Effectiveness of Trichoderma species applied into stone-wool and peat infested with Fusarium oxysporum f. sp. radices-lycopersici (Forl) and F. oxysporum f. sp. dianthi (Fod) in the control of Fusarium base rot of tomato and carnation Fusarium wilt was estimated. In three cycles of tomato production in stone-wool Fusarium stem base rot of tomato was observed in all treatments including noninfested combination. Application of Trichoderma spp. into stone-wool resulted in double decrease of total infected plants in the first year of cultivation and 7-fold time in the second year. In the third year of tomato production the disease was not observed. Preplanting application of Trichoderma viride into peat infested with Fod resulted in the significant decrease of Fusarium wilt of carnation. The antagonistic species cause the decrease of Fod population in the substratum.

Key words: biocontrol, Trichoderma, Fusarium oxysporum, tomato, carnation, effectiveness

\section{Streszczenie}

Oceniano przydatność gatunków rodzaju Trichoderma wprowadzonych do wełny mineralnej oraz substratu torfowego, zakażonych przez Fusarium oxysporum f. sp. radicis-lycopersici (Forl) i F. oxysporum f. sp. dianthi (Fod) na rozwój fuzaryjnej zgorzeli pomidorów i fuzariozy naczyniowej goździków. W 3 cyklach uprawy pomidorów w samej wełnie mineralnej, objawy fuzaryjnej zgorzeli wystąpiły we wszystkich kombinacjach, w tym na roślinach kontrolnych bez zakażenia Forl. Dodatek Trichoderma spp. do wełny mineralnej zakażonej przez Forl spowodował około 2-krotne obniżenie liczby porażonych pomidorów w pierwszym roku uprawy i 7-krotne w drugim roku. $W$ trzecim roku nie stwierdzono w nasadzeniu chorych roślin. Zastosowanie $T$. viride przedwegetacyjnie, do podłoża zakażonego Fod, spowodowało istotne ograniczenie rozwoju fuzariozy naczyniowej. Gatunek antagonistyczny, szczególnie zastosowany w wyższych dawkach, ograniczał rozwój Fod w podłożu.

Słowa kluczowe: biologiczna ochrona, Trichoderma, Fusarium oxysporum, pomidor, goździk, skuteczność

Instytut Ogrodnictwa

Zakład Ochrony Roślin Ozdobnych

Konstytucji 3 Maja 1/3, 96-100 Skierniewice

Leszek.orlikowski@inhort.pl 


\section{Wstęp / Introduction}

W uprawie warzyw i roślin ozdobnych pod osłonami bardzo duże straty powodowane są przez patogeny glebowe, w tym formy specjalne Fusarium oxysporum. Uważa się, że systemy hydroponiczne zapewniają uprawę roślin w warunkach sterylnych. Tymczasem patogeny mogą być wprowadzone do wełny mineralnej na rozsadzie, przenoszone na obuwiu lub ogumieniu pojazdów, a także z cząsteczkami pyłu (Jarvis 1988). Zdaniem Rowe i wsp. (1977) zarodniki form specjalnych $F$. oxysporum mogą być masowo przenoszone z prądami powietrza i dostawać się do wełny mineralnej. Ich nosicielami mogą być również ziemiórki i pleciuga brzegówka (Gillespie i Menzies 1993; Corbaz i Fischer 1994). Jarvis (1988) uważa, że F. oxysporum f. sp. radicis-lycopersici może być silnie redukowany przez jego naturalnych konkurentów i antagonistów. Wśród nich wymienia się Trichoderma harzianum (Marois i wsp. 1981). Mechanizm oddziaływania Trichoderma spp. na patogeny roślin omówił Pietr (1997).

W uprawie goździków szklarniowych nadal najgroźniejszym czynnikiem chorobotwórczym jest $F$. oxysporum f. sp. dianthi, a jego źródłem, obok zakażonego podłoża, mogą być sadzonki. Poza odkażaniem podłoża bardzo istotną rolę pełni ochrona roślin w trakcie ich uprawy z uwagi na niebezpieczeństwo wprowadzenia czynnika chorobotwórczego do nasadzeń z materiałem sadzeniowym. W Polsce, do biologicznej ochrony upraw pod osłonami przed $F$. oxysporum zarejestrowany jest i stosowany biopreparat Polyversum WP, oparty na Pythium oligandrum (Orlikowski i Jaworska-Marosz 2002). Niektórzy producenci stosują również stymulatory rozwoju roślin zawierające gatunki rodzaju Trichoderma. W literaturze istnieją tysiące danych dotyczących również oddziaływania gatunków tego rodzaju na patogeny roślin oraz mechanizmów ich działania. W Polsce, badania nad Trichoderma spp. i innymi czynnikami biologicznymi, jako potencjalnymi czynnikami ochronnymi, prowadzone były w minionym 40-leciu, w tym na goździkach i gerberze przez Orlikowskiego (1987, 1995), Orlikowskiego i Skrzypczaka (1987) oraz Webera i wsp. (1998).

Celem prowadzonych badań była ocena przydatności gatunków rodzaju Trichoderma, wprowadzonych do wełny mineralnej oraz substratu torfowego, zakażonych przez odpowiednie formy specjalne $F$. oxysporum, na ograniczenie rozwoju fuzariozy pomidora i goździka oraz oddziaływanie $T$. viride na zmiany $\mathrm{w}$ liczebności populacji F. oxysporum f. sp. dianthi.

\section{Materiały i metody / Materials and methods}

\section{Kultury badanych patogenów}

F. oxysporum f. sp. radicis-lycopersici (Forl) uzyskano $\mathrm{z}$ podstawy pędu pomidora, a $F$. oxysporum f. sp. dianthi (Fod) wyizolowano $\mathrm{z}$ wiązki przewodzącej porażonego goździka. Izolaty inkubowano na pożywce ziemniaczanoglukozowej (PDA - Potato Dextrose Agar) w temperaturze $25^{\circ} \mathrm{C}$, w ciemności.

\section{Kultury Trichoderma spp.}

Mieszaninę izolatów T. hamatum, T. harzianum i T. koningii $\mathrm{w}$ formie zarodników dodano do wełny mineralnej po ustawieniu kostek $\mathrm{z}$ pomidorami na macie oraz po 6 tygodniach uprawy $\mathrm{w}$ ilości $0,2 \mathrm{~g}$ na roślinę. $\mathrm{Z}$ kolei izolat T25 $T$. viride inkubowano na pożywce ziemniaczano-glukozowej w ciemności, w temperaturze $25^{\circ} \mathrm{C}$ przez 7 dni. Po tym czasie krążkami o średnicy $3 \mathrm{~mm}$ szczepiono szalki z pożywką z płatków owsianych i inkubowano je przez 2 tygodnie w temperaturze $25^{\circ} \mathrm{C}$. Następnie inokulum rozdrabniano w homogenizatorze $\mathrm{z}$ dodatkiem $10 \mathrm{ml}$ wody na szalkę. Przygotowaną zawiesinę dodawano do 201 substratu torfowego i mieszano dokładnie przez 15 minut, po czym inkubowano go przez 14 dni w workach foliowych $\mathrm{z}$ niewielkimi otworami. W badaniach użyto 50, 100 i $150 \mathrm{~g}$ inokulum $T$. viride na $1 \mathrm{~m}^{3}$ substratu torfowego zakażonego przez F. oxysporum f. sp. dianthi, które wymieszano z zakażonym podłożem 3 dni przed sadzeniem roślin.

\section{Inokulum $F$. oxysporum f. sp. dianthi}

Przygotowano je na pożywce z płatków owsianych podobnie, jak inokulum $T$. viride. Po wymieszaniu z substratem torfowym o pH 5,3 inkubowano go przez $14 \mathrm{dni}$ w workach, w temperaturze około $22^{\circ} \mathrm{C}$, po czym napełniano nim doniczki o pojemności 1 litra i sadzono goździki odmiany Master, wrażliwej na Fod.

\section{Określenie liczebności populacji Fod}

Określano ją przed wprowadzeniem do podłoża T. viride, a następnie po 5, 7, 9 i 11 tygodniach uprawy goździków, stosując pożywkę selektywną Komady (1975). W dwóch doświadczeniach inicjalna liczebność populacji patogena wynosiła odpowiednio 5900 i 6500 jednostek propagacyjnych w $1 \mathrm{~g}$ powietrznie suchego podłoża.

\section{Środki standardowe}

Topsin M 500 SC zastosowano doglebowo w stężeniu $0,1 \%$; w ilości 41 cieczy na $\mathrm{m}^{2}$ bezpośrednio po sadzeniu goździków do podłoża zakażonego przez Fod.

\section{Układ doświadczeń}

Założono je w układzie bloków kompletnie losowych w 4 powtórzeniach po 10 roślin i przeprowadzono je 2-3-krotnie.

\section{Wyniki i dyskusja / Results and discussion}

\section{Wpływ Trichoderma spp. na zdrowotność pomidorów w 3 cyklach ich uprawy}

Uprawa pomidorów w warunkach stałego zagrożenia przez Forl spowodowała, że w trzech latach badań fuzarioza zgorzelowa wystąpiła również na roślinach kontrolnych, niezakażonych (rys. 1). W kombinacji tej największe nasilenie choroby stwierdzono $\mathrm{w}$ drugim roku uprawy roślin w tej samej wełnie mineralnej. W trzecim roku uprawy liczba porażonych pomidorów obniżyła się 
z około 40 do 13\% (rys. 1). Uprawa pomidorów w wełnie mineralnej zakażonej przez Forl wiązała się z bardzo dużymi stratami z powodu dużego nasilenia występowania fuzariozy zgorzelowej. W pierwszym roku straty wynosiły około $60 \%$, a w następnych dwóch latach stwierdzono stopniowy spadek liczby porażonych roślin odpowiednio do 53 i $40 \%$ (rys. 1). Dwukrotna aplikacja Trichoderma spp. spowodowała drastyczne ograniczenie rozwoju choroby do $27 \% \mathrm{w}$ pierwszym roku i braku objawów w trzecim roku uprawy pomidorów (rys. 1).

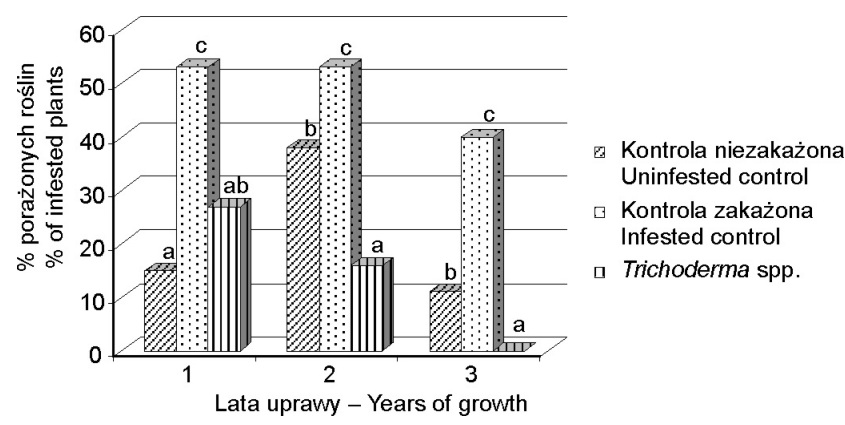

Średnie w kolumnach, oznaczone tą samą litera, nie różnią się istotnie $(5 \%)$ według testu Duncana

Means in columns, followed by the same letter do not differ $(5 \%)$ according to Duncan's multiple range test

Rys. 1. Współzależność pomiędzy okresem użytkowania wełny mineralnej zakażonej $F$. oxysporum f. sp. radicis-lycopersici oraz aplikacji Trichoderma spp. a zdrowotnością pomidorów szklarniowych

Fig. 1. Relationship between period of using stonewool infested with $F$. oxysporum f. sp. radicis-lycopersici, Trichoderma spp. application and health conditions conditions of tomato

\section{Wpływ Trichoderma spp. na zdrowotność goździków}

W pierwszym doświadczeniu (tab. 1), dodatek T. viride w dawce $50 \mathrm{~g} / \mathrm{m}^{3}$ podłoża, zakażonego przez Fod, nie spowodował istotnego obniżenia liczby goździków $\mathrm{z}$ objawami fuzariozy naczyniowej $w$ badanych okresach. Dodatek 100 i $150 \mathrm{~g} T$. viride na $\mathrm{m}^{3}$ substratu spowodował istotne ograniczenie rozwoju choroby w ciagu 11-tygodniowego okresu uprawy (tab. 1). Końcowa obserwacja, przeprowadzona po 11 tygodniach wzrostu goździków, wykazała wprawdzie nieznaczny, ale istotny spadek liczby porażonych roślin, szczególnie gdy $T$. viride wymieszano $\mathrm{z}$ podłożem w ilości $150 \mathrm{~g}$ inokulum $/ \mathrm{m}^{3}$ (tab. 1).

W drugim doświadczeniu, założonym 3 tygodnie później, w warunkach bardziej sprzyjających rozwojowi fuzariozy naczyniowej $\mathrm{z}$ uwagi na wyższą temperaturę i większe nasłonecznienie, objawów chorobowych nie stwierdzono po 5 tygodniach uprawy na goździkach chronionych $T$. viride. Po następnych 6 tygodniach uprawy istotnie mniej goździków z objawami choroby naczyniowej stwierdzono w podłożu z dodatkiem $T$. viride $\mathrm{w} 3$ różnych dawkach, w porównaniu z kombinacją kontrolną zakażoną. Po 11 tygodniach istotnie najskuteczniejszą okazała się $T$. viride w dawce $100 \mathrm{~g} / \mathrm{m}^{3}$. Srodek standardowy okazał się mniej skuteczny od antagonisty zastosowanego w ilości $100 \mathrm{~g} / \mathrm{m}^{3}$ podłoża (tab. 2).

Wysoka efektywność gatunków: Trichoderma hamatum, T. harzianum i T. koningii, dodanych dwukrotnie do wełny mineralnej w trakcie wiosennej uprawy pomidorów, powodowała w każdym roku zmniejszenie porażenia roślin przez $F$. oxysporum f. sp. radicis-lycopersici, przy czym efekt ten był istotny w drugim i trzecim roku produkcji. Jednocześnie, począwszy od drugiego roku uprawy notowano spadek liczby porażonych roślin w kombinacji kontrolnej - zakażonej. W badaniach Rattinka (1993) z 3 badanych gatunków Trichoderma najskuteczniejszym okazał

Tabela 1. Wpływ izolatu T25 T. viride, zastosowanego doglebowo 3 dni przed sadzeniem goździków odmiany Master do substratu torfowego zakażonego $F$. oxysporum $\mathrm{f}$. sp. dianthi, na ograniczenie występowania fuzariozy naczyniowej

Table 1. Influence of isolate T25 of $T$. viride applied three days before planting of carnation cultivar Master into peat infested with F. oxysporum f. sp. dianthi, on the development of Fusarium wilt

Sadzenie - Planting: 2011.05.12

Populacja inicjalna: 5600 jednostek propagacyjnych w $1 \mathrm{~g}$ powietrznie suchego podłoża Initial popultion: 5.600 of colony forming units/g of air dry peat

\begin{tabular}{|c|c|c|c|c|c|}
\hline \multirow{2}{*}{$\begin{array}{l}\text { Kombinacje } \\
\text { Treatments }\end{array}$} & \multirow{2}{*}{$\begin{array}{c}\text { Dawka lub stężenie } \\
\text { Dose or } \\
\text { concentration } \\
{\left[\mathrm{g} / \mathrm{m}^{3]}\right.}\end{array}$} & \multicolumn{4}{|c|}{$\begin{array}{l}\text { Liczba chorych roślin }(n=10) \text { po tygodniach od sadzenia } \\
\text { Number of diseased plants }(n=10) \text { after weeks of planting }\end{array}$} \\
\hline & & 5 & 7 & 9 & 11 \\
\hline $\begin{array}{l}\text { Kontrola niezakażona } \\
\text { Control uninfested }\end{array}$ & - & $0 \mathrm{a}$ & $0 \mathrm{a}$ & $0 \mathrm{a}$ & $0 \mathrm{a}$ \\
\hline $\begin{array}{l}\text { Kontrola zakażona } \\
\text { Control infested }\end{array}$ & - & $0 \mathrm{a}$ & $2,5 \mathrm{c}$ & $6,3 \mathrm{c}$ & $8,8 \mathrm{c}$ \\
\hline T. viride & 50 & $0,5 \mathrm{a}$ & $2,8 \mathrm{c}$ & $6,3 \mathrm{c}$ & $9,8 \mathrm{c}$ \\
\hline T. viride & 100 & $0,3 \mathrm{a}$ & $2,0 \mathrm{bc}$ & $4,5 \mathrm{~b}$ & $7,3 \mathrm{~b}$ \\
\hline T. viride & 150 & $0,3 \mathrm{a}$ & $2,0 \mathrm{bc}$ & $4,3 \mathrm{~b}$ & $6,5 \mathrm{~b}$ \\
\hline Topsin M $500 \mathrm{SC}$ & $0.1 \%$ & $0 \mathrm{a}$ & $1,3 \mathrm{~b}$ & $3,3 \mathrm{~b}$ & $6,8 \mathrm{~b}$ \\
\hline
\end{tabular}

Średnie w kolumnach, oznaczone tą samą literą, nie różnią się istotnie (5\%) według testu Duncana

Means in columns, followed by the same letter do not differ (5\%) according to Duncan's multiple range test 
Tabela 2. Wpływ izolatu T25 T. viride, zastosowanego doglebowo 3 dni przed sadzeniem goździków odmiany Master do podłoża zakażonego $F$. oxysporum f. sp. dianthi, na ograniczenie występowania fuzariozy naczyniowej

Table 2. Influence of isolate T25 of $T$. viride applied three days before planting of carnation cultivar Master into peat infested with $F$. oxysporum f. sp. dianthi, on the development of Fusarium wilt

Sadzenie - Planting: 2011.06.03 Populacja inicjalna: 6500 jednostek propagacyjnych w $1 \mathrm{~g}$ powietrznie suchego podłoża Initial population: 6.500 of colony forming units/g of air dry peat

\begin{tabular}{|c|c|c|c|c|c|}
\hline \multirow{2}{*}{$\begin{array}{l}\text { Kombinacje } \\
\text { Treatments }\end{array}$} & \multirow{2}{*}{$\begin{array}{c}\text { Dawka lub stężenie } \\
\text { Dose or } \\
\text { concentration } \\
{\left[\mathrm{g} / \mathrm{m}^{3]}\right.}\end{array}$} & \multicolumn{4}{|c|}{$\begin{array}{l}\text { Liczba chorych roślin }(n=10) \text { po tygodniach od sadzenia } \\
\text { Number of diseased plants }(n=10) \text { after weeks of planting }\end{array}$} \\
\hline & & 5 & 7 & 9 & 11 \\
\hline $\begin{array}{l}\text { Kontrola niezakażona } \\
\text { Control uninfested }\end{array}$ & - & $0 \mathrm{a}$ & $0 \mathrm{a}$ & $0 \mathrm{a}$ & $0,5 \mathrm{a}$ \\
\hline $\begin{array}{l}\text { Kontrola zakażona } \\
\text { Control infested }\end{array}$ & - & $1,3 \mathrm{~b}$ & $2,0 \mathrm{~b}$ & $5,0 \mathrm{c}$ & $8,3 \mathrm{~d}$ \\
\hline T. viride & 50 & $0 \mathrm{a}$ & $0,5 \mathrm{a}$ & $3,0 \mathrm{~b}$ & $5,5 \mathrm{c}$ \\
\hline T. viride & 100 & $0 \mathrm{a}$ & $0,3 \mathrm{a}$ & $2,5 \mathrm{~b}$ & $3,8 \mathrm{~b}$ \\
\hline T. viride & 150 & $0 \mathrm{a}$ & $0,8 \mathrm{a}$ & $2,8 \mathrm{~b}$ & $5,0 \mathrm{c}$ \\
\hline Topsin M 500 SC & $0.1 \%$ & $0 \mathrm{a}$ & $0 \mathrm{a}$ & $2,8 \mathrm{~b}$ & $5,5 \mathrm{c}$ \\
\hline
\end{tabular}

Średnie w kolumnach, oznaczone tą samą literą, nie różnią się istotnie (5\%) według testu Duncana

Means in columns, followed by the same letter do not differ (5\%) according to Duncan's multiple range test

się T. harzianum T35, substancja czynna biopreparatu Trichodex. Bardzo istotne okazało się wprowadzenie antagonisty $\mathrm{w}$ trakcie produkcji rozsady, $\mathrm{tj}$. przed czynnikiem chorobotwórczym. Uzyskane dane potwierdzają wyniki Marois i wsp. (1981), Sivan i wsp. (1987) oraz Ślusarskiego (1998), wskazujące na ograniczenie rozwoju fuzariozy zgorzelowej pomidora przez T. harzianum. Zdaniem Postmy i wsp. (2001) jest to związane ze wzrostem liczby mikroorganizmów antagonistycznych dla patogena i ograniczeniem jego liczebności w środowisku uprawy roślin.

Analiza efektywności $T$. viride w ograniczaniu rozwoju fuzariozy naczyniowej goździka wskazuje, że była ona wyraźnie wyższa w doświadczeniu założonym w czerwcu, gdy warunki atmosferyczne sprzyjały rozwojowi antagonisty w podłożu. Zmniejszenie liczby porażonych goździków o połowę przy dawce $T$. viride $100 \mathrm{~g} / \mathrm{m}^{3}$ i efektywność antagonisty istotnie wyższą aniżeli tiofanatu metylowego należy uznać za fakt zadawalający tym bardziej, że liczebność patogena w podłożu była około 2-krotnie wyższa aniżeli ma to miejsce $\mathrm{w}$ warunkach naturalnego wystąpienia fuzariozy naczyniowej.

\section{Oddziaływanie $T$, viride na $F$. oxysporum f. sp. dianthi w podłożu}

Po 5 tygodniach uprawy goździków stwierdzono zmniejszenie liczebności Fod w podłożu zarówno przez T. viride, jak i tiofanat metylowy, przy czym istotnie najskuteczniejszą (ograniczenie liczebności patogena o 41\%) okazała się dawka antagonisty w ilości $150 \mathrm{~g} / \mathrm{m}^{3}$ (rys. 2). Po 7 tygodniach liczebność Fod została obniżona o $62 \%$ i około $40 \%$, gdy $T$. viride wprowadzono do podłoża odpowiednio w dawkach $150 \mathrm{~g} / \mathrm{m}^{3}$ i niższych. Podobną skuteczność w ograniczeniu liczebności Fod stwierdzono po zastosowaniu tiofanatu metylowego. W następnych 9 i 11 tygodniach uprawy stwierdzono spadek aktywności $T$. viride, szczególnie w dawkach 50 i $100 \mathrm{~g} / \mathrm{m}^{3}$ oraz tiofanatu metylowego (rys. 2).

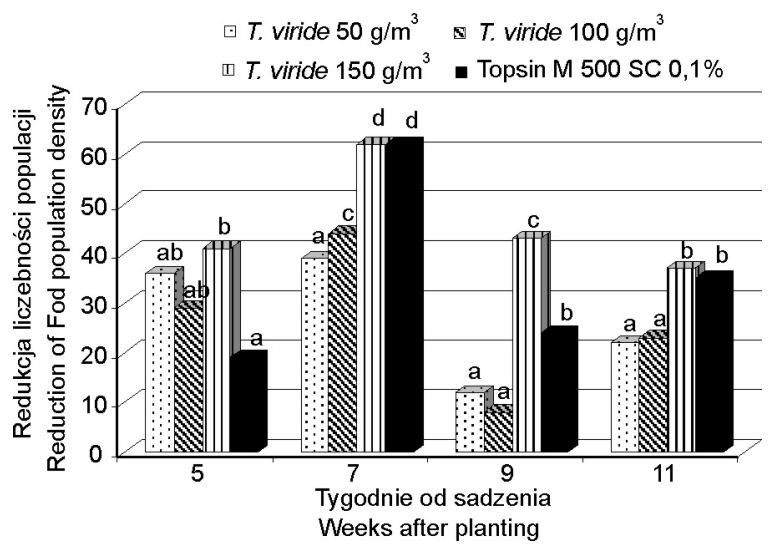

Średnie w kolumnach, oznaczone tą samą literą, nie różnią się istotnie (5\%) według testu Duncana

Means in columns, followed by the same letter do not differ (5\%) according to Duncan's multiple range test

Rys. 2. Współzależność pomiędzy dawkami T. viride i okresem uprawy goździków a zmianami w liczebności populacji Fusarium oxysporum f. sp. dianthi w substracie torfowym

Fig. 2. Relationship between $T$. viride doses, growing period and changing in population density of Fusarium oxysporum f. sp. dianthi in peat

\section{Wnioski / Conclusions}

1. Wymieszanie inokulum T. viride $\mathrm{z}$ podłożem zakażonym przez $F$. oxysporum f. sp. dianthi przed sadzeniem goździków spowodowało istotne ograniczenie fuzaryjnego więdnięcia w ciągu 11-tygodniowej uprawy.

2. Doglebowa aplikacja $T$. viride spowodowała obniżenie liczebności $F$. oxysporum f. sp. dianthi w substracie torfowym, szczególnie w ciągu pierwszych 7 tygodni 
uprawy, a w następnych 4 tygodniach aktywność antagonisty drastycznie spadła.

3. Gatunek antagonistyczny wykazywał najwyższą aktywność, gdy wprowadzono go do podłoża w ilości 100 i $150 \mathrm{~g} / \mathrm{m}^{3}$.
4. Wysoka aktywność Trichoderma spp. w uprawie pomidorów w wełnie mineralnej, zakażonej przez F. oxysporum $\mathrm{f}$. sp. radicis-lycopersici, była widoczna w trzecim roku uprawy roślin w tym samym podłożu.

\section{Literatura / References}

Corbaz R., Fisher S. 1994. La mouche Scatella stagnalis Fal. (Diptera: Ephydridae) responsible de la dispersion de Fusarium oxysporum f. sp. lycopersici dans les cultures de tomates hors sol. Arboric. Hortic. 26 (6): 383-385.

Gillespie D.R., Menzies J.G. 1993. Fungus gnats vector Fusarium oxysporum f. sp. radices-lycopersici. Ann. Appl. Biol. 123: 539-544.

Jarvis W.R. 1988. Fusarium crown and root rot of tomatoes. Phytoprotection 69: 49-64.

Komada H. 1975. Development of a selective medium for quantitative isolation of Fusarium oxysporum from natural soil. Rev. Plant Prot. Res. 8: 114-125.

Marois J.J., Mitchell D.J., Sonoda R.M. 1981. Biological control of Fusarium crown rot of tomato under field conditions. Phytopathology 71 (12): 1257-1260.

Orlikowski L.B. 1987. Wykorzystanie naturalnej oporności podłoży w ochronie goździków przed fuzariozą naczyniową. Rocz. Nauk Rol., Seria E, 16: 149-159.

Orlikowski L.B. 1995. Studies on biological control of Phytophthora cryptogea Pethybr. et Laff. II. Effectiveness of Trichoderma and Gliocladium spp. in the control of Phytophthora foot rot of gerbera. J. Phytopathol. 143: 341-343.

Orlikowski L.B., Jaworska-Marosz A. 2002. Influence of Pythium oligandrum on population of Fusarium oxysporum f. sp. dianthi and development of Fusarium wilt of carnation. Plant Prot. Sci. 38 (1): 209-211.

Orlikowski L.B., Skrzypczak Cz. 1987. Effectiveness of Fusaclean in the control of five formae specialis of Fusarium oxysporum Schlecht. on some ornamental plants. Phytopathol. Pol. 13: 49-57.

Pietr S.J. 1997. The mode of action of Trichoderma: short summary. Trichoderma spp., other microorganisms and plant extracts in plant disease control. p. 7-14. In: Proc. 8th Conference of the section for Biological Control of Plant Diseases of the Pol. Phytopath. Soc. Skierniewice, April 21-22, 1997, 165 pp.

Postma J., Willemsen-de Klein M.J.E.I.M., Van Elsas E.A., Rattink H. 2001. Disease suppressive soiless culture systems; characterisation of its microflora. Acta Hortic. 554: 323-331.

Rattink H. 1993. Biological control of Fusarium crown and root rot in tomato on a recirculation substrate system. Med. Fac. Landbouww. Rijksuniv. Gent 58: 1329-1336.

Rowe R.C., Farley J.D., Coplin D.L. 1977. Air-borne spore dispersal and recolonisation of steamed soil by Fusarium oxysporum in tomato greenhouses. Phytopathology 67: 1513-1517.

Sivan A., Ucko O., Chet I. 1987. Biological control of Fusarium crown rot of tomato by Trichoderma harzianum under field conditions. Plant Dis. 71 (7): 587-592.

Ślusarski Cz. 1998. Biological control of Fusarium oxysporum f. sp. radices-lycopersici on greenhouse tomato in soiless culture. Biological agents and their effectiveness in the control of plant pathogens. p. 78-83. In: Proc. 9th Conference of the Section for Biological Control of Plant Diseases of Pol. Phytopathol. Soc. Skierniewice, April 23-24, 1998, 202 pp.

Weber Z., Werner M., Frużyńska-Jóźwiak D. 1998. Biological protection of carnation, asparagus and babies breath against particular formae speciales of Fusarium oxysporum Schlecht. Phytopathol. Pol. 16: 37-43. 